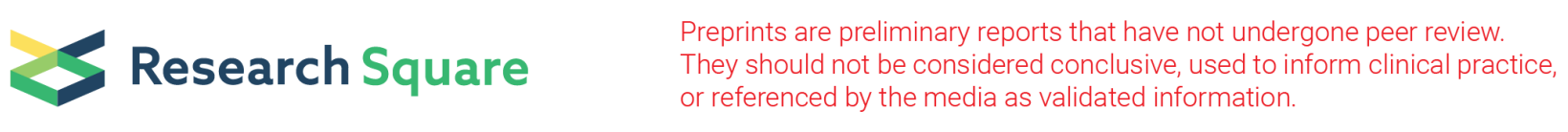

\title{
Growth and physio-biochemical responses of Azolla filiculoides subjected to short span of phenol exposure
}

Bittu Paul

University of North Bengal

Ashis Sarkar

University of North Bengal

Swarnendu Roy ( $\square$ swarnendubotany@nbu.ac.in )

University of North Bengal https://orcid.org/0000-0001-8239-6683

\section{Research Article}

Keywords: Plant growth, Macrophytes, Water pollution, Growth, Antioxidative enzymes, Reactive oxygen species

Posted Date: April 16th, 2021

DOI: https://doi.org/10.21203/rs.3.rs-416354/v1

License: (c) (i) This work is licensed under a Creative Commons Attribution 4.0 International License. Read Full License 


\section{Abstract}

Phenol and phenolic compounds are one of the major water pollutants increasing at an alarming rate due to uncontrolled anthropogenic activities. Aquatic plants are in the frontline to face the toxic effects of these pollutants. The present study attempts to study the effect of external phenols on a floating fern Azolla filiculoides. In this context, the effect of four concentrations of crystalline phenol $(0.5,1,2$ and $3 \mathrm{mM})$ along with a control set ( 0 mM) were used to evaluate the changes in the responses of $A$. filiculoides plants in terms of the major morphological, physiological and biochemical markers, after being exposed for 3 and 6 days. In this study, relative growth rate, relative frond number, relative frond surface area, relative water content, chlorophyll a and carotenoids decreased significantly both with increasing phenol concentration and also with the duration of treatment. Frond necrotic area, electrolyte leakage and malondialdehyde content increased significantly which demonstrated the negative effects of phenol. However, increase in proline content, total sugars, activities of antioxidative enzymes like superoxide dismutase, catalase and peroxidase indicated the presence of an inherent tolerance mechanism in this plant. Accumulation of $\mathrm{H}_{2} \mathrm{O}_{2}$ also supported by the in situ localization of $\mathrm{H}_{2} \mathrm{O}_{2}$ along with the changes in growth parameters and physio-biochemical indicators demonstrated that the extent of phenol toxicity increased with the increasing concentrations of phenol. The overall findings also suggest that the $A$. filiculoides plants can maintain their growth and physiology up to a concentration of $1 \mathrm{mM}$ phenol.

\section{Introduction}

Water pollution directly or indirectly affects all life forms. Presently all water-bodies like ponds, lakes, rivers, oceans, and even groundwater are highly polluted or under extreme threat of pollution. A significant number of water pollutants either belongs to phenolic group of compounds or produces phenolic compounds upon degradation (Kulkarni and Kawar, 2013). Phenol is mostly a colorless, water-soluble molecule that consists of a benzene ring along with at least one functional hydroxyl group. US Environmental Protection Agency have enlisted about 11 types of phenolic pollutants viz. Phenol, 2,4,6-trichlorophenol, p-chloro-m-cresol, 2-chlorophenol, 2,4-dichlorophenol, 2,4-dimethylphenol, 2-nitrophenol, 4-nitrophenol, 2,4-dinitrophenol, 4,6-dinitro-o-cresol, and pentachlorophenol in their priority list of toxic pollutants (Kieth, 1980). Common sources of phenolic compounds in the aquatic ecosystem originates from industry, sewage, agricultural and also from household wastes (Anku et al., 2017; Stewart and Stewart, 2008).

There has been a lot of concerns regarding the presence of phenolic compounds in aquatic ecosystems off late. Zhong et al. (2018) have found the presence of about 50 phenolic compounds from 3 different rivers in Tianjin, China. They quantified the concentrations of phenols in surface water, suspended particulate matter and sediments in the range of $1.35 \mathrm{mg} / \mathrm{L}, 0.719 \mathrm{mg} / \mathrm{Kg}$ dry weight and $2.94 \mathrm{mg} / \mathrm{Kg}$ dry weight respectively. Another report by Busca et al. (2008) have suggested the presence of organic pollutants in wastewater comprising of phenols in the range of 2.8 to $6800 \mathrm{mg} / \mathrm{L}$, which was mainly attributed to the effluents from different industries like manufacturing units, petrochemical refineries, coal processing units etc.

A large number of works have been conducted to assess the effect of phenolic compounds on aquatic fauna. However, very few studies have focused on the effect of phenolic compounds on aquatic plants. On the basis of these works, it has been found that the aquatic plants respond differently to varying concentrations of phenolic compounds but the basic mechanism to resist the negative impacts of these toxic compounds is more or less similar (Jagetiya et al., 2013; Wasi et al., 2013). Inhibition of plant multiplication and reduction of growth was observed in Lemna minor and Elodia canadensis subjected to concentrations above $10^{-3}$ moles/L, that exhibited the phytotoxic effect of phenols on these macrophytes (Stom and Roth, 1981). According to Scragg (2006), Chlorella VT-1 shows more tolerance against the phenolic compounds upto a concentration of $400 \mathrm{mg} / \mathrm{L}$, when compared to Chlorella vulgaris which is relatively less tolerant. At $400 \mathrm{mg} / \mathrm{L}$ phenol, $44 \%$ growth inhibition was observed in Chlorella VT-1, whereas growth of Chlorella vulgaris at the same concentration was completely inhibited. Similarly, reduction in frond multiplication was observed in Lemna paucicostata as a consequence of increasing phenol concentration (Park et al., 2012). On the other hand, several plants have been known to maintain their normal growth and physiology at higher concentrations of phenol by uptaking and utilizing the excess amount of phenols from the surrounding. Chang et al. (2020) reported that the submerged macrophyte - Hydrilla verticillata was capable to absorb and degrade phenolic compounds when exposed to $100 \mathrm{mg} / \mathrm{L}$ concentration with minute physiological effects. Lee et al., (2017) calculated the rate of removal of phenols using Ipomoea aquatica that showed about $72.2 \%$ survival rate when exposed to $300 \mathrm{mg} / \mathrm{L}$ phenol. They have shown that the plant was capable to remove phenol at the rate of $21 \mathrm{mg} / \mathrm{L} / \mathrm{day}$. Similarly, enhancement in the biomass of Lemna minuta plants was observed owing to its ability to utilize the phenolic compounds (Paisio et al., 2018).

Azolla filiculoides is a free-floating small aquatic fern, that exhibits the ability to grow rapidly, and double its biomass within 3-5 days (Arora and Saxena, 2005). The association of Azolla with the diazotroph Anabaena azollae also boost the growth of this plant where nitrogen availability is low (Sood et al., 2008). Azolla spp. has been known to accumulate heavy metals like Zn, Fe, and Mn from the surrounding (Sood et al., 2012). These attributes of $A$ zolla has been valued for the removal of water pollutants in aquatic ecosystem (Mashkani and Ghazvini, 2009; Rai, 2008). A previous study by Ali et al. (2013) have reported the usage of dried Azolla filiculoides biomass to absorb 2, 4, 6-trichlorophenol from the aqueous solution. However, no studies have been conducted to assess the effect of phenol on the growth and physio-biochemical responses of Azolla filiculoides.

Therefore, this study attempts to provide an insight in to the responses of Azolla filiculoides plants to different concentrations of phenol. For this purpose, the effect of phenol was evaluated in terms of morphological indicators such as relative growth rate, relative fond number (RFN), relative frond surface area (RFSA) and frond necrotic area (FNA). Physiological parameters like relative water content (RWC), electrolyte leakage (EL) and membrane lipid peroxidation were also observed. Most importantly, the effect of phenol exposure on the biochemical indicators of plants like the changes in osmolyte accumulation, photosynthetic pigments, enzymatic antioxidants and reactive oxygen species (ROS) were analyzed.

\section{Materials And Methods}

\subsection{Plant material and experimental setup}


A laboratory based experiment was carried out in the Plant Biochemistry Laboratory, Department of Botany, University of North Bengal during summer season, 2019. Azolla filiculoides, a free-floating aquatic fern, a member of Azollaceae was chosen for the present experiment. The plant was collected from a pond, near the University of North Bengal (NBU) campus, Siliguri, India during the month of March, 2019. After collecting the plants, it was transferred to a water tank $\left(200 \times 60 \mathrm{~cm}^{2}\right)$ in the experimental garden of the department. The water tank was fertilized every 7 days with $1 \mathrm{~g} / \mathrm{L}$ solution of magnesium chloride, rock phosphate and potassium (2:3:1 w/w/w) to support the growth of the plants and thereafter the mature plants of same age were relocated to the laboratory, where they were transferred to beakers containing 0.1X Hoagland solution (Gamborg and Wetter, 1975). The plants were then allowed to acclimatise for a week in laboratory conditions. For the experimental setup, four different concentrations of crystalline phenol viz. 0.5, 1, 2, and 3 mM were prepared in $0.1 \mathrm{X}$ Hoagland solutions along with $0 \mathrm{mM}$ solution as the control set. Equal number of plants were transferred to beakers containing the treatment solutions in a plant growth chamber $\left(25^{\circ}-28^{\circ} \mathrm{C}\right.$ temperature and $70 \%-75 \% \mathrm{RH}$ with $16: 8$ hours of light and dark photoperiod condition maintained). Two different duration of treatment viz. 3 days (shorter duration) and 6 days (longer duration) was selected to evaluate the responses of plants subjected to different phenol concentrations.

\subsection{Growth and morphological attributes}

To determine relative growth rate (RGR), fresh weights of the plants were initially measured $\left(W_{0}\right)$ before the start of phenol treatments. After 3 and 6 days of treatment, the weight $\left(\mathrm{W}_{\mathrm{t}}\right)$ of the same plants were taken and the relative growth rate was measured with the following equation -

Other indicators of morphological changes observed in the plants subjected to phenol treatments were determined in terms of relative frond number (RFN), relative frond surface area (RFSA) and frond necrotic area (FNA). All the parameters were analysed from the captured images of plants at the end of treatment regime using Fiji-Image $\mathrm{J}$ software.

To measure the RFN, frond number of plants were counted at 0 days $\left(N_{0}\right)$, 3 days and 6 days $\left(N_{t}\right.$ where $t=3$ or 6 days). RFN was measured using following formula -

For RFSA, initial frond surface area at 0 days $\left(A_{0}\right)$ and final frond surface area ( $A_{t}$ where $t=3$ or 6 days) at 3 and 6 days was measured. RFSA was calculated by the following formula -

For FNA, necrotic area of all the sets were measured at 0,3 and 6 days $\left(\mathrm{NA}_{t}\right.$ where $\mathrm{t}=0$ or 3 or 6 days) and determined in terms of percentage of the total frond surface area of the respective sets $\left(A_{t}\right.$ where $t=3$ or 6 days). FNA was calculated using the following equation -

\subsection{Relative water content (RWC), Electrolyte leakage (EL) and Malondialdehyde content (MDA)}

Relative water content (RWC) was measured according to the standard protocol described by Barr and Weatherley (1962). The whole plants were utilized for the experiment. Fresh weight (F.W), turgid weight (T.W) and dry weight (D.W) was taken as described. Relative Water Content was measured with the following equation -

Electrolyte leakage was measured as described by Lutts et al. (1996). The control and treated plant samples were washed thoroughly with double distilled water. Then the plants along with $10 \mathrm{~mL}$ of deionized water were incubated in a rotary shaker for $24 \mathrm{~h}$ at $25^{\circ} \mathrm{C}$. Then the initial electrical conductivity was measured $\left(L_{0}\right)$, after that, it was autoclaved and the final electrical conductivity was measured $\left(L_{t}\right)$ after cooling. Electrolyte leakage was calculated as follows

$$
\text { Electrolyteleakage }(\backslash \%)=\frac{\mathrm{Lt}}{\mathrm{L} 0} \times 100
$$

Membrane lipid peroxidation (MDA content) was measured following the described method of Heath and Packer (class="CitationRef" $>1968)$ with slight modifications. Plants were homogenized in $0.1 \%$ TCA and centrifuged at $10,000 \mathrm{rpm}$, then the supernatant was collected. $0.5 \%$ of TBA in $20 \%$ TCA and $1 \mathrm{~mL}$ of supernatant was heated at $95^{\circ} \mathrm{C}$ for $30 \mathrm{~min}$, after that it was cooled on ice. Absorbance was finally taken at $532 \mathrm{~nm}$ and $600 \mathrm{~nm}$. MDA content was calculated using an extinction co-efficient of $155 \mathrm{mM}^{-1} \mathrm{~cm}^{-1}$.

\subsection{Extraction and estimation of photosynthetic pigments}

Chlorophyll was estimated according to the method of Harborne (1973) with slight modifications by homogenizing the plant materials $(0.5 \mathrm{~g})$ in $80 \%$ acetone and centrifuged at $8000 \mathrm{rpm}$ for $10 \mathrm{~min}$. The supernatants were collected and the absorbance was taken at $470 \mathrm{~nm}, 647 \mathrm{~nm}$, and $663 \mathrm{~nm}$ in a UV-VIS spectrophotometer against a blank of $80 \%$ acetone to estimate chlorophylls and carotenoids using the formula as given by Lichtenthaler (1987) -

Chlorophyll a (12.25xA663) - (2.79xA647) $\mu \mathrm{g} / \mathrm{mL}$

Chlorophyll b = (21.5xA647) $-(5.1 \times A 663) \mu \mathrm{g} / \mathrm{mL}$

$$
\text { Totalcarotenoids }=\frac{[(1000 \times \mathrm{A} 470)-(1.82 \times \mathrm{Chla})-(85.02 \times \mathrm{Chlb})]}{198} \mu \mathrm{g} / \mathrm{mL}
$$

\subsection{Extraction and estimation of osmolytes}


Extraction of proline from the plant material was done by the method of Bates et al. (1973) with slight changes. Plant tissue (1 g) was homogenized in $3 \%$ sulfosalicylic acid $(10 \mathrm{~mL})$ and centrifuged at $8000 \mathrm{rpm}$ for $10 \mathrm{~min}$ at room temperature and the supernatant was collected for estimation. The reaction mixture absorbance was measured spectrophotometrically at $520 \mathrm{~nm}$ Proline content estimated using a standard curve of L-proline.

For the extraction of total sugar, Harborne's (1973) method was followed. The treated plants along with control set was taken for ethanolic extraction (95\%) and estimation of total sugar was done by Anthrone reagent following the method of Plummer (1978). A standard curve of D-glucose was used for the quantification.

\subsection{Extraction and estimation of antioxidative enzymes}

The treated plants along with control plants were homogenized in $50 \mathrm{mM}$ sodium phosphate buffer, $\mathrm{pH} 6.8$ (for peroxidase and catalase enzymes; $\mathrm{pH} 7.2$ for ascorbate peroxidase enzyme along with $1 \mathrm{mM}$ of ascorbate) and $100 \mathrm{mM}$ potassium phosphate buffer $\mathrm{pH} 7.6$ (for superoxide dismutase and glutathione reductase) under ice-cold conditions. The homogenates were centrifuged at $10,000 \mathrm{rpm}$ at $4^{\circ} \mathrm{C}$ for $15 \mathrm{~min}$. Fresh supernatants were used as crude enzyme extracts and estimation of protein content was done in each case following the method of Bradford (1976).

The activity of superoxide dismutase (SOD) was determined following the method of Dhindsa et al. (1981) with some minor adjustments. The reaction mixture contained $1.5 \mathrm{~mL}$ of $0.1 \mathrm{M}$ potassium phosphate buffer ( $\mathrm{pH} 7.6$ ), $0.5 \mathrm{~mL}$ of $\mathrm{dH}_{2} \mathrm{O}, 0.2 \mathrm{~mL}$ of $0.2 \mathrm{M}$ methionine (freshly prepared), $0.2 \mathrm{~mL}$ of $2.25 \mathrm{mM}$ $\mathrm{NBT}, 0.1 \mathrm{~mL}$ of $1.5 \mathrm{M} \mathrm{Na}_{2} \mathrm{CO}_{3}, 0.1 \mathrm{~mL}$ of $3 \mathrm{mM}$ EDTA (freshly prepared), $0.2 \mathrm{~mL}$ of $60 \mu \mathrm{M}$ riboflavin, and $0.2 \mathrm{~mL}$ of enzyme extract. The reaction mixture were illuminated for 10 minutes. The absorbance was taken at the wavelength of $560 \mathrm{~nm}$ in a UV-VIS spectrophotometer. $50 \%$ reduction of NBT compared to the control set containing no enzyme extract was represented to have 1 Unit of enzyme activity (EU).

Glutathione reductase (GR) activity was determined by Lee and Lee (2000) by measuring the oxidation of NADPH ( $€=6.2 \mathrm{mmol}-1 \mathrm{~cm}-1)$ with minor modifications. The reaction mixture consisted of $1 \mathrm{~mL}$ of $0.1 \mathrm{M}$ potassium buffer ( $\mathrm{pH} 7.6), 0.2 \mathrm{~mL}$ of $100 \mathrm{mM} \mathrm{EDTA}, 0.2 \mathrm{~mL}$ of $0.1 \mathrm{mM} \mathrm{NADPH}$ and $0.2 \mathrm{~mL}$ of enzyme extract, along with $0.1 \mathrm{~mL}$ of $6 \mathrm{mM}$ glutathione (freshly prepared). The immediate change in absorbance of the reaction mixture was measured after every 30 seconds up to 3 min using a UV-VIS spectrophotometer at $340 \mathrm{~nm}$.

Ascorbate peroxidase (APX) activity was assayed following the method of Asada and Takahashi (1987) with slight modification. The reaction mixture consisted of $0.01 \mathrm{~mL}$ of freshly prepared ascorbic acid, $0.01 \mathrm{~mL}$ of $\mathrm{H}_{2} \mathrm{O}_{2}, 2.97 \mathrm{~mL}$ of $50 \mathrm{mM}$ sodium phosphate buffer ( $\mathrm{pH} 7.2$ ) and $0.01 \mathrm{~mL}$ of enzyme extract. Reduction of absorbance was measured at $290 \mathrm{~nm}$ at regular intervals up to 3 minutes in a UV-VIS spectrophotometer.

Peroxidase (POX) activity was determined by following the method of Chakraborty et al. (1993). The reaction mixture consisted of $1 \mathrm{~mL}$ of $100 \mathrm{mM}$ sodium phosphate buffer $(\mathrm{pH} 6.8), 1.7 \mathrm{~mL}$ of $\mathrm{dH}_{2} \mathrm{O}, 0.1 \mathrm{~mL}$ of $\mathrm{H}_{2} \mathrm{O}_{2}, 0.1 \mathrm{~mL}$ of o-dianisidine, and $0.1 \mathrm{~mL}$ enzyme extract. Changes in absorbance was taken at $460 \mathrm{~nm}$ at regular intervals up to 3 minutes in a UV-VIS spectrophotometer.

Catalase (CAT) activity was assayed using the method of Chance and Machly (1955). $100 \mu$ of the enzyme extract was added in $2.9 \mathrm{~mL}$ of $\mathrm{H}_{2} \mathrm{O}_{2}$-phosphate buffer. Changes in absorbance were taken immediately at $240 \mathrm{~nm}$ in a UV-VIS spectrophotometer at regular intervals up to 3 minutes in a UV-VIS spectrophotometer.

\subsection{Extraction and estimation of total phenol}

For the extraction of phenols, Mahadevan and Sridhar's (1982) method was followed. For the extraction, plants were crushed in $80 \%$ ethanol in dark and the filtrate was collected. Estimation of total phenol content was done following the method of Bray and Thorpe (1954). Briefly, the filtrate was mixed with Folin Ciocalteu's reagent and $20 \% \mathrm{Na}_{2} \mathrm{CO}_{3}$ solution and the absorbance was recorded at $650 \mathrm{~nm}$. The total phenol content was calculated using a standard curve of catechol.

\subsection{Hydrogen peroxide $\left(\mathrm{H}_{2} \mathrm{O}_{2}\right)$ content and in situ localization}

The extraction and estimation of $\mathrm{H}_{2} \mathrm{O}_{2}$ were done by the method of Jana and Choudhuri (1981) with slight modifications. $0.5 \mathrm{~g}$ of plant sample was homogenized in $10 \mathrm{~mL}$ of $50 \mathrm{mM}$ phosphate buffer $(\mathrm{pH}$ 6.5). The homogenate was centrifuged at $6000 \mathrm{rpm}$ for 25 minutes. After that $3 \mathrm{~mL}$ of the supernatant was mixed with $1 \mathrm{~mL}$ of $0.1 \%$ titanium sulphate and centrifuged at $6000 \mathrm{rpm}$ for 15 minutes. Finally, the absorbance was measured at $410 \mathrm{~nm}$ in a UV-VIS spectrophotometer.

For the detection of $\mathrm{H}_{2} \mathrm{O}_{2}$ inside the plant tissue, the method of Thordal-Christensen et al. (1997) with minor modifications was followed. The plants were washed thoroughly with $\mathrm{dH}_{2} \mathrm{O}$ and then incubated in dark for $24 \mathrm{~h}$ in $1 \mathrm{mg} / \mathrm{mL}$ of 3, 3'-Diaminobenzidine (DAB) (pH 3.8). After $24 \mathrm{~h}$ the whole plant was transferred to a beaker containing ethanol, lactic acid and glycerol in the ratio 4:1:1 and boiled in dark until all the chlorophyll was removed from the fronds. Visualization of the $\mathrm{H}_{2} \mathrm{O}_{2}$ stained region was done over an illuminated platform.

\subsection{Statistical analysis}

All the experiments were conducted in replicates $(\mathrm{N}=3)$. Values shown in the figures and tables represent the average values \pm standard deviation $(\mathrm{SD})$ for all the treatment sets. One-way ANOVA was performed using IBM SPSS version 22 and the post-hoc analysis of the results were performed through Duncan's test taking a significance level of $p \leq 0.05$. Correlation analysis was performed between the concentrations of phenol and all the parameters after 3 days and 6 days separately using two tailed Pearson's correlation co-efficient analysis in IBM SPSS version 22.

\section{Results}




\subsection{Effect of phenol exposure on the growth and morphological attributes (RGR, RFN, RFSA and FNA)}

The varying effect of the different concentrations of phenol on Azolla filiculoides plants was evident through the morphological appearance of the plants after the treatment regimes. With the increasing concentrations of phenol, marked impact was clearly visualized on the fronds in the form of necrotic lesions. Further inference on the effect of phenol on the plants were evaluated in terms of relative growth rate (RGR), relative frond number (RFN), Relative frond surface area (RFSA) and frond necrotic area (FNA).

After 3 days of treatment, RGR of the plants was found to be significantly reduced in comparison to the control subjected to treatments with higher concentrations of phenol ( $\geq 2 \mathrm{mM}$ ). However, after longer duration of treatment RGR reduced significantly at all the phenol concentrations (Fig. $1 \mathrm{~A})$. This decrease in RGR ranged from 15-257\% in comparison to the control set. Similarly, after 3 and 6 days of treatment, both RFN and RFSA were also found to gradually decrease with the increase in phenol concentrations, except in case of the plants treated with $0.5 \mathrm{mM}$ phenol for 3 days (Fig. 1B-C). Highest decrease in the range of $106-121 \%$ in case of RFN and 148-169\% for RFSA were observed in the plants treated with 3 mM phenol for 3 and 6 days. However, with the increase in phenol concentration and duration of treatment, FNA was found to be significantly enhanced (Fig. 1D). The extent of necrotic lesions was maximum in case of $3 \mathrm{mM}$ treated plants, where more than $80 \%$ of the tissue was found to be affected.

\subsection{Effect on water status and membrane stability (RWC, EL and MDA)}

Relative water content (RWC) was found to decrease significantly in comparison to the control plants with increasing concentrations of phenol both after 3 and 6 days of treatment (Table 1). Approximately, $90 \%$ RWC was observed in the plants exposed to 0.5 and 1 mM phenol concentrations for 3 and 6 days. Also, after longer duration of treatment, RWC was found to decrease in comparison to that of 3 days across all the concentrations. Status of membrane integrity was evaluated through electrolyte leakage and membrane lipid peroxidation (MDA content). The electrolyte leakage increased with increasing phenol concentration for short as well as longer duration of exposure. Highest leakage in the order of $725-895 \%$ was observed in case of plants treated with 3 mM phenol concentration for 3 and 6 days respectively when compared to the control set (Table 1). Similarly, after 3 and 6 days of treatment, MDA was generally found to increase at all the concentrations. (Table 1). At $3 \mathrm{mM}$ phenol treated plants, this increase in MDA ranged from 185-322\% in comparison to the control set.

Table 1

Effect of different concentrations of phenol on relative water content (RWC), electrolyte leakage (EL), MDA content, proline content and total soluble sugar content

\begin{tabular}{|c|c|c|c|c|c|c|c|c|c|c|}
\hline \multirow[t]{2}{*}{$\begin{array}{l}\text { Conc. of phenol } \\
\text { (mM) }\end{array}$} & \multicolumn{2}{|c|}{$\begin{array}{l}\text { Relative water } \\
\text { content (\%) }\end{array}$} & \multicolumn{2}{|c|}{ Electrolyte leakage (\%) } & $\begin{array}{l}\text { MDA content } \\
\text { (nM/g F.W.) }\end{array}$ & \multicolumn{2}{|c|}{$\begin{array}{l}\text { Proline content } \\
\text { (mg/g F.W.) }\end{array}$} & \multicolumn{3}{|c|}{$\begin{array}{l}\text { Total soluble sugar content } \\
\text { (mg/g F.W.) }\end{array}$} \\
\hline & 3 Day & 6 Day & 3 Day & 6 Day & 3 Day & 6 Day & 3 Day & 6 Day & 3 Day & 6 Day \\
\hline 0 & $\begin{array}{l}95.32 \pm \\
0.54^{\mathrm{e}}\end{array}$ & $\begin{array}{l}95.27 \pm \\
0.55^{\mathrm{e}}\end{array}$ & $\begin{array}{l}6.82 \pm \\
1.12^{\mathrm{a}}\end{array}$ & $\begin{array}{l}6.75 \pm \\
0.58^{\mathrm{a}}\end{array}$ & $\begin{array}{l}6.18 \pm \\
0.53^{\mathrm{a}}\end{array}$ & $\begin{array}{l}6.68 \pm \\
0.62^{\mathrm{a}}\end{array}$ & $\begin{array}{l}0.041 \pm \\
0.001^{\mathrm{b}}\end{array}$ & $\begin{array}{l}0.043 \pm \\
0.001^{b}\end{array}$ & $\begin{array}{l}2.01 \pm \\
0.02^{\mathrm{a}}\end{array}$ & $\begin{array}{l}2.05 \pm \\
0.10^{\mathrm{a}}\end{array}$ \\
\hline 0.5 & $\begin{array}{l}93.56 \pm \\
0.42^{d}\end{array}$ & $\begin{array}{l}92.62 \pm \\
1.52^{d}\end{array}$ & $\begin{array}{l}8.45 \pm \\
0.37^{a}\end{array}$ & $\begin{array}{l}11.70 \pm \\
0.53^{\mathrm{a}}\end{array}$ & $\begin{array}{l}7.21 \pm \\
0.43^{\mathrm{ab}}\end{array}$ & $\begin{array}{l}8.24 \pm \\
0.43^{\mathrm{a}}\end{array}$ & $\begin{array}{l}0.011 \pm \\
0.001^{a}\end{array}$ & $\begin{array}{l}0.13 \pm \\
0.011^{c}\end{array}$ & $\begin{array}{l}2.83 \pm \\
0.04^{\mathrm{c}}\end{array}$ & $\begin{array}{l}2.67 \pm \\
0.18^{b}\end{array}$ \\
\hline 1 & $\begin{array}{l}89.86 \pm \\
0.60^{c}\end{array}$ & $\begin{array}{l}88.14 \pm \\
0.82^{c}\end{array}$ & $\begin{array}{l}12.22 \pm \\
0.49^{b}\end{array}$ & $\begin{array}{l}30.73 \pm \\
5.48^{\mathrm{b}}\end{array}$ & $\begin{array}{l}7.78 \pm \\
0.54^{\mathrm{ab}}\end{array}$ & $\begin{array}{l}19.11 \pm \\
0 . .46^{\mathrm{b}}\end{array}$ & $\begin{array}{l}0.061 \pm \\
0.002^{\mathrm{C}}\end{array}$ & $\begin{array}{l}0.162 \pm \\
0.005^{d}\end{array}$ & $\begin{array}{l}2.47 \pm \\
0.27^{b}\end{array}$ & $\begin{array}{l}2.82 \pm \\
0.16^{b}\end{array}$ \\
\hline 2 & $\begin{array}{l}84.71 \pm \\
1.23^{\mathrm{b}}\end{array}$ & $\begin{array}{l}78.79 \pm \\
0.17^{b}\end{array}$ & $\begin{array}{l}37.20 \pm \\
2.92^{\mathrm{c}}\end{array}$ & $\begin{array}{l}47.85 \pm \\
4.07^{c}\end{array}$ & $\begin{array}{l}9.93 \pm \\
0.24^{b}\end{array}$ & $\begin{array}{l}21.87 \pm \\
0.34^{\mathrm{c}}\end{array}$ & $\begin{array}{l}0.058 \pm \\
0.002^{c}\end{array}$ & $\begin{array}{l}0.046 \pm \\
0.002^{b}\end{array}$ & $\begin{array}{l}3.31 \pm \\
0.19^{d}\end{array}$ & $\begin{array}{l}2.76 \pm \\
0.14^{b}\end{array}$ \\
\hline 3 & $\begin{array}{l}81.71 \pm \\
0.49^{\mathrm{a}}\end{array}$ & $\begin{array}{l}71.00 \pm \\
1.56^{\mathrm{a}}\end{array}$ & $\begin{array}{l}56.36 \pm \\
2.44^{d}\end{array}$ & $\begin{array}{l}67.15 \pm \\
1.66^{d}\end{array}$ & $\begin{array}{l}17.65 \pm \\
0.38^{\mathrm{c}}\end{array}$ & $\begin{array}{l}28.22 \pm \\
1.75^{d}\end{array}$ & $\begin{array}{l}0.040 \pm \\
0.003^{b}\end{array}$ & $\begin{array}{l}0.008 \pm \\
0.003^{a}\end{array}$ & $\begin{array}{l}2.69 \pm \\
0.14^{\mathrm{bc}}\end{array}$ & $\begin{array}{l}2.00 \pm \\
0.29^{a}\end{array}$ \\
\hline
\end{tabular}

All the values represent Mean \pm S.D. Different letters in superscripts indicate significant differences in the mean values subjected to different concentrations of phenol separately for 3 days and 6 days of exposure.

\subsection{Effect on the pigment compositions}

The amount of chlorophyll a and chlorophyll b of the plants increased at lower concentrations, but significantly reduced at higher concentrations when compared to the control set after shorter duration of treatment (Fig. 2A). At highest concentration (3mM), chlorophyll a and chlorophyll b decreased approximately by $22 \%$ and $59 \%$ respectively. Moreover, chlorophyll a content of the plants reduced by more than $50 \%$ exposed to highest phenol concentration for 6 days. In contrast, the amount of chlorophyll b was found to be enhanced (64-162\%) at all the concentrations in comparison to the control set. Carotenoid content was generally observed to be reduced with increasing phenol concentration both after shorter and longer duration of treatments, but this decrease was more significant in the plants exposed for longer duration when compared to the control set (Fig. 2B). This decline in carotenoid content after 6 days of treatment ranged from $15-36 \%$ in comparison to control set.

\subsection{Effect on osmolyte accumulation}

Accumulation of proline was found to be highest in plants exposed to $1 \mathrm{mM}$ phenol concentration ( $0.061 \mathrm{mg} / \mathrm{g}$ for 3 days and $0.162 \mathrm{mg} / \mathrm{g}$ for 6 days). Moreover, the accumulation of proline was found to be increased after 6 days of treatment in comparison to that of the 3 day treated plants across all the concentrations (Table 1). For instance, maximum increase in the accumulation of proline (164\%) was observed in plants treated with $1 \mathrm{mM}$ phenol concentration for 6 days when compared to that of the 3 day set. 
Total soluble sugar content was generally observed to increase with increasing phenol concentrations both after shorter and longer duration of treatments except in the plants exposed to $3 \mathrm{mM}$ phenol for 6 days. But the increase was more significant in the plants exposed for shorter duration when compared to the control set. The extent of this increase in total sugar content ranged from 22-64\% in the phenol treated plants in comparison to control set.

\subsection{Status of the enzymatic antioxidants and total phenols}

The activity of superoxide dismutase (SOD) was found to increase significantly in plants exposed to phenol concentrations $\geq 1 \mathrm{mM}$ when compared to the control set after 3 days of treatment (Fig. 3A). Moreover, SOD activity of the phenol treated plants showed an increase up to $2 \mathrm{mM}$ phenol treated plant after 6 days of exposure in comparison to the control sets. In this regard, the highest increase of $155 \%$ was observed in case of $2 \mathrm{mM}$ treated plants than control.

A decrease in the activity of glutathione reductase (GR) was observed in comparison to the control, when the plants were exposed for shorter duration of treatments (Fig. 3B). This decline in enzyme activity was found in the order of 44-63\%. However, after 6 days of treatment a sharp enhancement in GR activity was recorded in case of $3 \mathrm{mM}$ treated plants when compared to the control and also with respect to that of the plants treated with the same phenol concentration for shorter duration (510\% increase from the 3 day plants).

The ascorbate peroxidase (APX) activities were found to increase with increasing phenol concentrations ( $\geq 2 \mathrm{mM})$ after 3 days (Fig. 3C). At the highest concentration, APX activity increased by approximately $30 \%$ than the control. After longer duration of treatment, APX activity was increased except in 2 mM phenol treated plant. Highest ascorbate peroxidase activity increased $293 \%$ in $3 \mathrm{mM}$ phenol concentration in compare with control.

The peroxidase (POX) activity enhanced with increasing concentrations of phenol in comparison to control after 3 days of treatments, except at the highest concentration ( $3 \mathrm{mM})$ where a significant decline (33\% from the control) was observed (Fig. 3D). Also, after 6 days of treatment, significant decline in POX activity ( $68 \%$ from the control) was recorded in case of $3 \mathrm{mM}$ phenol treated plants. Moreover, POX activity declined in the plants exposed to 2 and $3 \mathrm{mM}$ phenol for 6 days when compared to that of the 3 day treated plants.

A significant enhancement in catalase (CAT) activity was observed in case of plants treated with higher concentrations ( $\geq 2 \mathrm{mM}$ phenol) for shorter duration. Highest activity in this regard was observed in case of $2 \mathrm{mM}$ phenol treated plants which was approximately $45 \%$ more than the control plants (Fig. $3 \mathrm{E}$ ). However, after longer duration of treatment, CAT activity was found to increase initially but at higher concentrations, the activity was found to be reduced significantly than the control.

Total phenolics also considered as non-enzymatic antioxidants was generally found to be significantly decreased in comparison to the control plants subjected to shorter duration of exposure, except at $0.5 \mathrm{mM}$ treated plants (Fig. 3F). At $2 \mathrm{mM}$ phenol concentration, highest decrease of $38 \%$ from the control was observed. However, in the plants exposed for longer duration, total phenol content significantly increased up to $1 \mathrm{mM}$ concentration, but at higher concentrations the amount of that total phenols significantly reduced. Moreover, total phenol content increased at all the concentrations (11-67\%) after 6 days of treatment in comparison to that of the 3 day treated plants.

\subsection{Effect on the accumulation of $\mathrm{H}_{2} \mathrm{O}_{2}$ and in situ localization}

In the present study, the $\mathrm{H}_{2} \mathrm{O}_{2}$ content increased significantly with increasing phenol concentrations both after 3 and 6 days of treatment (Fig. $4 \mathrm{~A}$ ). The accumulation $\mathrm{H}_{2} \mathrm{O}_{2}$ was found to be highest at $3 \mathrm{mM}$ phenol treated plants which ranged from $129-252 \%$ in comparison to the control set. Similar trends were observed with the DAB stained fronds to locate the accumulation of $\mathrm{H}_{2} \mathrm{O}_{2}$ in the plant tissues. The presence of $\mathrm{H}_{2} \mathrm{O}_{2}$ was observed as reddish-brown patches formed due to the complexation of $\mathrm{H}_{2} \mathrm{O}_{2}$ and DAB (Fig. 4B). After 3 and 6 days of treatment, this reddish-brown patches gradually increased with the increasing phenol concentrations. Also, the reddish-brown patches were found to be comparatively more after 6 days in comparison to that of the 3 days treated plants.

\subsection{Correlation analysis between the concentration of phenols and the other parameters}

After 3 days of treatment, exposure to external phenol was positively correlated with the increase of FNA, EL, MDA, total soluble sugar, SOD, APX, CAT, $\mathrm{H}_{2} \mathrm{O}_{2}$ while, negatively correlated with RGR, RWC, chlorophyll a and b, and tissue phenol content (Table 2). Relative growth rate was found to be positively correlated with RFN, RFSA, RWC, Chl a and b, whereas it was negatively correlated with EL, MDA, carotenoids, APX, and $\mathrm{H}_{2} \mathrm{O}_{2}$ which may have accounted for the reduction in growth rate. The photosynthetic pigments such as chl a and b was positively correlated with RGR, RFN, RFSA, RWC and negatively correlated with phenol, FNA, EL, MDA, APX, CAT, $\mathrm{H}_{2} \mathrm{O}_{2}$. Increased amount of $\mathrm{H}_{2} \mathrm{O}_{2}$ was observed to induce the activity of SOD and APX enzymes, whereas at the same time it enhanced the electrolyte leakage and MDA content which resulted in the appearance of necrotic lesions. 


\begin{tabular}{|c|c|c|c|c|c|c|c|c|c|c|c|c|c|c|}
\hline \multicolumn{15}{|l|}{$\mathrm{H}_{2} \mathrm{O}_{2}$} \\
\hline \multicolumn{15}{|l|}{ TP } \\
\hline \multicolumn{15}{|l|}{ CAT } \\
\hline \multicolumn{15}{|l|}{ POX } \\
\hline \multicolumn{15}{|l|}{ APX } \\
\hline \multicolumn{15}{|l|}{ GR } \\
\hline SOD & & & & & & & & & & & & & & 1 \\
\hline CAR & & & & & & & & & & & & & 1 & 0.1 \\
\hline CHLB & & & & & & & & & & & & 1 & -0.382 & -0.3 \\
\hline CHLA & & & & & & & & & & & 1 & $.956^{\star \star}$ & $-.514^{\star}$ & -0.5 \\
\hline SUG & & & & & & & & & & 1 & -0.412 & -0.304 & 0.44 & 0.4 \\
\hline PRO & & & & & & & & & 1 & 0.266 & $-.856^{\star \star}$ & $-.894 * \star$ & 0.083 & 0.4 \\
\hline MDA & & & & & & & & 1 & 0.048 & 0.036 & -0.175 & -0.004 & 0.032 & .71 \\
\hline EL & & & & & & & 1 & 0.227 & $.897^{\star \star}$ & 0.472 & $-.965^{\star \star}$ & $-.921^{\star \star}$ & 0.386 & .63 \\
\hline RWC & & & & & & 1 & $-.954 * \star$ & -0.377 & $-.845^{\star \star}$ & $-.563^{\star}$ & $.882^{\star \star}$ & $.810 * \star$ & -0.309 & -.7 \\
\hline FNA & & & & & 1 & $-.938^{\star \star}$ & $.944^{\star \star}$ & 0.326 & $.803^{\star \star}$ & $.540 *$ & $-.934^{\star \star}$ & $-.848^{\star *}$ & 0.431 & $.69^{\prime}$ \\
\hline RFSA & & & & 1 & $-.757 * \star$ & $.817 \star \star$ & $-.845^{\star \star}$ & -0.289 & $-.850 \star \star$ & -0.303 & $.807 * \star$ & $.784^{\star \star}$ & -0.098 & -0.4 \\
\hline RFN & & & 1 & $.709 \star \star$ & $-.918^{\star \star}$ & $.924^{\star \star}$ & $-.924^{\star \star}$ & -0.465 & $-.729 \star \star$ & -0.502 & $.882^{\star \star}$ & $.784^{\star \star}$ & -0.442 & -.8 \\
\hline RGR & & 1 & $.791^{\star \star}$ & $.631^{\star}$ & $-.738^{\star \star}$ & $.664^{\star \star}$ & $-.782^{\star \star}$ & -0.284 & $-.628^{\star}$ & -0.248 & $.858 * \star$ & $.782^{\star \star}$ & $-.638^{*}$ & -0.3 \\
\hline \multirow[t]{2}{*}{ CONP } & 1 & $-.674^{\star \star}$ & $-.924 \star \star$ & $-.817 \star \star$ & $.949 * \star$ & $-.984^{\star \star}$ & $.975^{\star \star}$ & 0.276 & $.893^{\star \star}$ & $.528^{\star}$ & $-.905^{\star \star}$ & $-.860 * \star$ & 0.269 & .73 \\
\hline & CONP & RGR & RFN & RFSA & FNA & RWC & EL & MDA & PRO & SUG & CHLA & CHLB & CAR & sol \\
\hline
\end{tabular}

Conversely, after 6 days of treatment, external phenol was found to be positively correlated with FNA, EL, MDA, GR, APX and was negatively correlated with RGR, RFN, RFSA, RWC, proline, chlorophyll a, CAT and tissue phenol (Table 3). RGR increased due to the increase of RFN, RFSA, RWC, chlorophyll a. But membrane lipid peroxidation, activities of $\mathrm{GR}, \mathrm{APX}$, and $\mathrm{H}_{2} \mathrm{O}_{2}$ content did not have any contribution towards positive growth rate. RWC was positively correlated with chlorophyll a, which increased RGR, RFN and RFSA. Also the $\mathrm{H}_{2} \mathrm{O}_{2}$ content was observed to be positively correlated with FNA, EL, MDA, GR, APX and negatively correlated with RWC, Chl a, CAT and tissue phenol content. 


\begin{tabular}{|c|c|c|c|c|c|c|c|c|c|c|c|c|c|c|}
\hline \multicolumn{15}{|l|}{$\mathrm{H}_{2} \mathrm{O}_{2}$} \\
\hline \multicolumn{15}{|l|}{ TP } \\
\hline \multicolumn{15}{|l|}{ CAT } \\
\hline \multicolumn{15}{|l|}{ POX } \\
\hline \multicolumn{15}{|l|}{ APX } \\
\hline \multicolumn{15}{|l|}{ GR } \\
\hline SOD & & & & & & & & & & & & & & 1 \\
\hline CAR & & & & & & & & & & & & & 1 & -0.4 \\
\hline CHLB & & & & & & & & & & & & 1 & $-.624^{\star}$ & 0.05 \\
\hline CHLA & & & & & & & & & & & 1 & -0.3 & 0.47 & -0.1 \\
\hline SUG & & & & & & & & & & 1 & -0.078 & $.646 * *$ & $-.789 * *$ & 0.35 \\
\hline PRO & & & & & & & & & 1 & -0.048 & $-.935^{\star \star}$ & 0.04 & -0.375 & $0.2=$ \\
\hline MDA & & & & & & & & 1 & -0.357 & $.679^{\star *}$ & 0.179 & $.691^{\star \star}$ & -0.365 & -0.1 \\
\hline EL & & & & & & & 1 & -0.493 & $.972^{\star *}$ & -0.126 & $-.926^{\star *}$ & -0.022 & -0.317 & 0.25 \\
\hline RWC & & & & & & 1 & $-.981^{\star *}$ & $.555^{\star}$ & $-.951^{\star \star}$ & 0.189 & $.901^{\star \star}$ & 0.027 & 0.276 & -0.2 \\
\hline FNA & & & & & 1 & $-.951^{\star \star}$ & $.933^{\star \star}$ & $-.593^{\star}$ & $.885^{\star \star}$ & -0.083 & $-.828^{\star \star}$ & -0.09 & -0.361 & $0.3 \varepsilon$ \\
\hline RFSA & & & & 1 & $-.855^{\star \star}$ & $.891^{\star \star}$ & $-.879 \star \star$ & 0.487 & $-.861^{\star \star}$ & 0.263 & $.822^{\star \star}$ & 0.087 & 0.274 & -0.2 \\
\hline RFN & & & 1 & $.846^{\star \star}$ & -0.937 & $.957^{\star *}$ & $-.976^{\star \star}$ & 0.427 & $-.953^{\star \star}$ & -0.012 & $.936^{\star \star}$ & -0.082 & 0.455 & -0.3 \\
\hline RGR & & 1 & $.944^{\star \star}$ & $.876^{\star *}$ & $-.911^{\star \star}$ & $.964^{\star \star}$ & $-.970^{\star \star}$ & 0.488 & $-.958^{\star *}$ & 0.201 & $.918^{\star \star}$ & 0.048 & 0.237 & -0.0 \\
\hline \multirow[t]{2}{*}{ CONP } & 1 & $-.970^{\star \star}$ & $-.971^{\star \star}$ & $-.880^{\star *}$ & $.940 \star *$ & $-.993^{\star \star}$ & $.986^{* *}$ & $-.518^{*}$ & $.952^{\star \star}$ & -0.154 & $-.929 * \star$ & 0.017 & -0.291 & 0.24 \\
\hline & CONP & RGR & RFN & RFSA & FNA & RWC & EL & MDA & PRO & SUG & CHLA & CHLB & CAR & So[ \\
\hline
\end{tabular}

\section{Discussion}

Phenol as a water pollutant has been known to have variable impacts on the normal growth, physiology and biochemistry of plants. A number of studies have attempted to evaluate the effect of phenol and different phenolic compounds (BPA, polyphenols, etc.) on macrophytes like Hydrilla verticillata, Ipomoea aquatica, Azolla filiculoides, Lemna minor and Elodia canadensis (Chang et al., 2020, Lee et al., 2017, Zazouli et al., 2014, Stom and Roth, 1981). In the present study, the effect of different concentrations of phenol was evaluated on the performance of Azolla filiculoides which is a commonly growing weed in the water bodies. The experimental results indicated that under the effect of phenol exposure, growth rate of $A$. filiculoides plant decreased significantly after 6 days of treatment (longer duration of exposure), and this decrease in growth rate enhanced with the increasing concentrations of phenol (Fig. 1A). Also, the effect on the growth was maximum incase of $3 \mathrm{mM}$ phenol treated plants. This decrease in growth rate could also be associated with the simultaneous decrease in the generation of new fronds with the increasing concentrations of phenol (Fig. 1B). This type of reduction in growth was previously reported in case of $A$ zolla pinnata plants exposed to two different pesticides - chlorpyrifos and cypermethrin (Prasad et al., 2015). Also, Sood et al. (2011) reported that Azolla microphylla exposed to $\geq 20 \mu \mathrm{M}$ paraquat concentration for 10 hours exhibited the maximum effect on plant growth. Moreover, in the present study the relative surface area of the plants were found to decrease under the effect of phenol concentrations $\geq 1 \mathrm{mM}$ both after 3 and 6 days of treatment (Fig. 1C). The decrease in growth rate and surface area of the plants could be correlated with the extent of phenol injury that were evident in the form of black necrotic lesions on the fronds which increased with the increase in phenol concentrations (Fig. 1D). Similar type of necrotic lesions have been observed in Salvinia auriculata when the plants were exposed to cadmium for 10 days (Wolff et al., 2012). These findings clearly indicate that the $A$. filiculoides plants are sensitive to increasing concentrations of phenols which affect the plant growth significantly.

In the present study, the extent of decrease in relative water content (RWC) was maximum in plants subjected to higher concentrations ( $\geq 2 \mathrm{mM}$ ) of phenol (Table 1). Due to the decrease in RWC, plants are subject to osmotic stress which affects the growth rate, by impairing the physiological processes such as decreasing stomatal conductance and $\mathrm{CO}_{2}$ assimilation (Lawlor, 2002). Decrease in RWC also destabilizes the photosynthetic machinery and directly impacts the plant productivity (Zhang et al., 2020). Exposure to increasing phenol concentrations also elevated the MDA contents in A. filiculoides, which may be due to the increase in the peroxidation of membrane lipids (Table 1). Moreover, the impact of phenol on the membrane integrity could be understood in terms of increasing electrolyte leakage with the increase in the concentrations of phenol. Under stressed conditions plants generates free radicals in significant amount, which get stuck into membrane lipids and generates lipid hydroperoxide. The peroxidized membranes are affected by elevated electrolyte leakage and reduction of membrane-fluidity (Kapoor et al., 2016). Similar enhancements in the MDA content of Azolla microphylla plants subjected to increasing concentrations of an insecticide - endosulfan have been shown to be related with the potential of this toxic compound to disturb the membrane stability (Raja 
et al., 2012a). In an aquatic species Chang et al. (2020) observed that Hydrilla verticillata exposed to phenol shows an increased amount MDA content. Therefore, it is quite evident from our results that the phenolic compounds directly affect the membrane integrity of $A$. filiculoides plants, especially at higher concentrations.

Chlorophyll and carotenoids are essential photosynthetic pigments and the status of these pigments in plants under stressed environment holds the key for their survival. A. filiculoides plants under the exposure of external phenol triggers a considerable change in the pigment composition. After 3 days of treatment, chlorophyll $a$ and $b$ increased at lower concentrations (Fig. 2A) which may be due its ability to resist low concentrations of phenol toxicity. However, at higher concentrations, both after 3 and 6 days of treatment chlorophyll a decreased significantly. This decline may result due to the disruption of photosystem as reported by Sánchez-Viveros et al. (2011). They have also reported while working on the effect of arsenic on $A$. filiculoides, that the chlorophyll a content remained almost unchanged up to a concentration of $\leq 30 \mu \mathrm{g} / \mathrm{mL}$ of the heavy metal, while it decreased at higher concentrations ( $\geq 60 \mu \mathrm{g} / \mathrm{mL}$ ). Carotenoids are the accessory pigments and also confer some protective mechanism to cope up with oxidative stress (Roberts et al., 2014). In our study, with shorter duration of exposure to phenol, carotenoid content does not show any significant changes with increasing concentrations of phenol, but it was found to decrease along with the increase in duration of treatment (Fig. 2B). A similar report of reduction in carotenoid content has been observed in another species of Azolla, when the plants were exposed to lead. This decline in carotenoid content has been attributed to the degradation of pigments due to an increased accumulation of ROS (Roberts et al., 2014).

Accumulation of an enhanced levels of osmolytes in plant tissues can help the plants to cope up with the negative impacts of osmotic stress (Samarina et al., 2020). Osmolytes such as soluble sugars and proline increased at all the concentrations of phenol after shorter duration of exposure. After longer duration of treatment, this enhancement was observed only in case of plants exposed to lower concentrations ( $\leq 1 \mathrm{mM})$ (Table 1). A positive correlation between abiotic stress tolerance and free proline accumulation has been reported by Martinez et al. (2016). In our study, the enhanced accumulation of proline was observed in 6 day treated plants in comparison to the 3 day treated plants across all the concentrations of phenol. This may be due to the presence of tolerance mechanism in plants up to a certain extent, which may assist the plants to survive in stressed condition. Abscisic acid dependent proline biosynthesis from glutamic acid, inhibition of proline degradation, reduction of protein biosynthesis may contribute to the elevated accumulation of free proline (Cao et al., 2020; Rana et al., 2017; Ren et al., 2018). In a similar experiment depicting the effect of an insecticide - monocrotrophos on Azolla microphylla, proline content was found to increase significantly (Raja et al., 2012b). However, the decrease of proline and total soluble sugars in Azolla filiculoides at highest phenol concentration ( $3 \mathrm{mM}$ ) after 6 days pointed towards the inability of the macrophyte to tolerate such high concentrations of phenol (Table 1). This findings are also in accordance with the changes in the growth pattern of the plants observed morphologically as well as through the other indicators.

Under oxidative stress extensive increase in internal phenolic compounds, which also functions as non-enzymatic antioxidants plays a key role in cellular homeostasis. In shorter duration of treatments, the phenol content of plants decreased. This may be due to the elicitation of oxidative stress and osmotic imbalance inside the plants under the effect of external phenol treatment. However, in our results, we have observed an increase in the tissue phenol content across all the concentrations with the longer duration of treatment, which indicates a certain level of tolerance mechanism in A. filiculoides (Fig. 3F). Similar findings have been reported an increase in the tissue phenolics of Azolla imbricata plants with the duration of treatment subjected to different concentrations of cadmium (Dai et al., 2006). Among the different types of ROS, $\mathrm{H}_{2} \mathrm{O}_{2}$ is the prime representative with relative stability and longer half-life which can determine the cellular stability. From our results, $\mathrm{H}_{2} \mathrm{O}_{2}$ content and in situ localization gives a clear view of the impact of increasing toxicity with the increasing concentrations of phenol on A. filiculoides (Fig. 4A-B). The enhanced levels of $\mathrm{H}_{2} \mathrm{O}_{2}$ promotes oxidative stress as well as activates the antioxidative machinery by actively regulating the cellular signaling to protect the plants (Mittler, 2002, Prasad and Singh, 2011).

The phenol induced toxicity creates imbalance by generation of free radicals of oxygen, which triggers the cellular antioxidative defense mechanism in plants. The major players in this protective mechanism are antioxidative enzymes such as superoxide dismutase (SOD), catalase (CAT), ascorbate peroxidase (APX), peroxidase (POX), glutathione reductase (GR) and several other non-enzymatic antioxidants. Enhanced activity of these antioxidative enzymes helps plants to counteract the oxidative stress (Soares et al., 2019). As a primary response to oxidative stress, SOD converts the highly unstable and reactive superoxide radicals to comparatively less harmful $\mathrm{H}_{2} \mathrm{O}_{2}$ to protect major cellular organelles. In the present study, remarkable increase in SOD activity at higher phenol concentrations subjected to longer duration of treatment reveals that the A. filiculocoides plant possess the capability to catalyze the increased amount of superoxide radicals (Fig. 3A). A similar observation has been reported in a different macrophyte - Salvinia natans, where on exposure to copper and glyphosate separately or in combined form led to the enhanced activity of SOD (Liu et al., 2019). The enhancement in the generation of $\mathrm{H}_{2} \mathrm{O}_{2}$ by the action of SOD triggers a set of antioxidative enzymes to eliminate $\mathrm{H}_{2} \mathrm{O}_{2}$. Although $\mathrm{H}_{2} \mathrm{O}_{2}$ is an important cellular signaling molecule, it can also hamper several metabolic pathways and lead to destruction of cell organelles. Therefore, to eliminate excessive $\mathrm{H}_{2} \mathrm{O}_{2}$ accumulated in plant tissues, a set of antioxidative enzymes like catalase (CAT), peroxidase (POX), ascorbate peroxidase (APX), glutathione reductase (GR), etc. play their essential part in the scavenging mechanism (Saxena et al., 2016). In our study, enhanced CAT activity was observed in plants exposed to phenol for shorter duration, however, the CAT activity was found to decline after being subjected to longer duration of treatment (Fig. 3E). Devi and Prasad (1998) have also reported an enhancement in the activity of CAT in a free floating macrophte - Ceratophyllum demersum subjected to copper toxicity. The increased activity of CAT effectively assist the plants to cope up with oxidative stress imparted by the toxic water pollutants. But at higher concentrations of these pollutants, this enzyme do not provide much protection to the plants, which is also observed in case of the present study. The peroxidase isozymes (POX and APX) also plays a remarkable part in the scavenging of excessive $\mathrm{H}_{2} \mathrm{O}_{2}$. In our study, the APX and POX activities were found to be elevated at lower phenolic treatments, after which a considerable reduction was observed at higher concentrations of phenol (Fig. 3C-D). This indicates towards the inefficiency of the antioxidative machinery of the plants to provide sufficient protection at higher concentrations. The enhanced POX and APX activities evidently enables the plant to employ a system for the coordinated elimination of peroxides and bypass the cellular damage, which has been previously observed on experiments with Salvinia molesta in response to arsenite toxicity (da Silva, 2018). Also, in the present study, the increased activity of POX and APX helped the A. filiculoides to perform better at lower phenol concentration. Along with the scavenging of $\mathrm{H}_{2} \mathrm{O}_{2}$, for the detoxification of xenobiotics, and for controlling the equilibrium between GSSG and GSH ascorbate-glutathione cycle GR plays an important role during stressed condition (Vilvert, 2017). Apart from APX, GR is an essential component of ascorbate-glutathione cycle and effectively regulates

Page $9 / 15$ 
the accumulation of $\mathrm{H}_{2} \mathrm{O}_{2}$. In the present study, in response to increasing phenol concentrations, noticeable reduction in the activity of GR was observed (Fig. 3B). Also the, GR activity in plants subjected to lower concentrations of phenol did not show any significant increase from the 3 day treated plants. Similarly, in response to the exposure to oxitetracyline - a toxic water pollutant, Egria densa also shows a decline in the activity of GR which clearly suggests the relatively lesser importance of this enzyme in the detoxification of $\mathrm{H}_{2} \mathrm{O}_{2}$ when compared to the other antioxidative enzymes (Vilvert, 2017).

\section{Conclusion}

The growth parameters, pigment contents and enhanced activities of antioxidative enzymes provides clear evidence that $A$. filiculoides can maintain its normal growth and physiology up to a considerable level at lower phenol concentrations. Our results indicated that the $A$. filiculocoides plants show tolerance upto a concentration of $1 \mathrm{mM}$ phenol under laboratory conditions and above this concentration significant damages could be observed morphologically, physiologically and biochemically. The extent of tissue injury and accumulation of ROS like $\mathrm{H}_{2} \mathrm{O}_{2}$ manifested by the plants exposed to higher concentrations of phenol for longer durations have clearly indicated the sensitivity of the plants. This sensitivity was also well reflected by the tissue damage in the form of necrotic lesions on the fronds and cessation in the growth of newer fronds. Though we have used crystalline phenol as a representative phenol compound to assess its toxicity on Azolla filiculoides for the present study, still the results clearly indicate the potential of this plant to be used as a biological indicator for the rapid detection of other phenolic pollutants in water bodies. In this connection, further studies are required to be conducted to understand the molecular mechanism of the impact of phenolic pollutants on this plant. Moreover, the potential of this macrophyte should be evaluated for its ability to accumulate phenolic compounds and the probable strategies for phenol degradation in the aquatic ecosystem.

\section{Declarations}

\section{Author Statement}

All the authors contributed equally to the work. Specific contribution of the authors is as follows:

Bittu Paul: Data curation, Funding acquisition, Investigation, Methodology, Software, Writing - Original draft.

Ashis Sarkar: Data curation, Funding acquisition, Investigation, Methodology, Software, Writing - Original Draft.

Swarnendu Roy: Conceptualization, Funding acquisition, Methodology, Supervision, Software, Writing - Review and Editing.

All the authors have read and approved the final manuscript.

\section{Conflict of interests}

The authors declare that they have no known competing financial interests or personal relationships that could have appeared to influence the work reported in this paper.

\section{Acknowledgements}

The authors acknowledge the grants received from University Grants Commission, India on account of fellowships Bittu Paul [UGC Ref. No. 713/(CSIR-UGC NET DEC 2018)]) and (Ashis Sarkar [UGC Ref. No. 685/(CSIR-UGC NET DEC 2018)] that enabled the present work to be conducted smoothly. The corresponding author acknowledges the University of North Bengal for providing the necessary infrastructures and partial assistance for chemicals required for conducting this work.

\section{References}

Ali, M., Balarak, D., Mahdavi, Y., (2013). Application of Azolla for 2,4,6-trichlorophenol (TCP) removal from aqueous solutions. Archives of hygiene sciences, 2 , 143-149.

Anku, W.W., Mamo, M.A., Govender, P.P., (2017). Phenolic compounds in water: Sources, reactivity, toxicity and treatment methods, in: Phenolic compounds Natural sources, importance and applications. InTech. https://doi.org/10.5772/66927

Asada, K., Takahashi. M., (1987). Production and scavenging of active oxygen in photosynthesis. DJ Kyle, CB Osmond, CJ Arntzen, Photoinhibition. Elsevier, Amsterdam, 227-287.

Arora, A., Saxena, S., (2005). Cultivation of Azolla microphylla biomass on secondary-treated Delhi municipal effluents. Biomass and Bioenergy, $29,60-64$.

Bates, L.S., Waldren, R.P., Teare, I.D., (1973). Rapid determination of free proline for water-stress studies. Plant Soil, 39, $205-207$.

Barrs, H.D. and Weatherley, P.E. (1962). A re-examination of the relative turgidity techniques for estimating water deficits in leaves. Australian Journal of Biological Sciences, 15, 413-428.

Bradford, M.M., (1976). A rapid and sensitive method for the quantitation of microgram quantities of protein utilizing the principle of protein-dye binding. Analytical Biochemistry, 72, 248-254.

Bray, H.G., Thorpe, W. V., (1954). Analysis of phenolic compounds of interest in metabolism. Methods Biochemical Analysis, 1, 27-52. 
Busca, G., Berardinelli, S., Resini, C., Arrighi, L., (2008). Technologies for the removal of phenol from fluid streams: A short review of recent developments. Journal of Hazardous Materials, 160, 265-288.

Cao, X., Wu, L., Wu, M., Zhu, C., Jin, Q., Zhang, J., (2020). Abscisic acid mediated proline biosynthesis and antioxidant ability in roots of two different rice genotypes under hypoxic stress. BMC Plant Biology, 20, 198.

Chakraborty, U., Chakraborty, B.N., Kapoor, M., (1993). Changes in the levels of peroxidase and phenylalanine ammonia-lyase in Brassica napus cultivars showing variable resistance to Leptosphaeria maculans. Folia Microbiolologica, 38, 491-496.

Chang, G., Yue, B., Gao, T., Yan, W., Pan, G., (2020). Phytoremediation of phenol by Hydrilla verticillata (L.f.) Royle and associated effects on physiological parameters. Journal of Hazardous Materials, 388, 121569.

da Silva, A.A., de Oliveira, J.A., de Campos, F.V., Ribeiro, C., Farnese, F. dos S., Costa, A.C., (2018). Phytoremediation potential of Salvinia molesta for arsenite contaminated water: role of antioxidant enzymes. Theoretical and Experimental Plant Physiology, 30, 275-286.

Dai, L.-P., Xiong, Z.-T., Huang, Y., Li, M.-J., (2006). Cadmium-induced changes in pigments, total phenolics, and phenylalanine ammonia-lyase activity in fronds of Azolla imbricata. Environmental Toxicology, 21, 505-512.

Dhindsa, R.S., Plumb-dhindsa, P., Thorpe, T.A., (1981). Leaf senescence: Correlated with increased levels of membrane permeability and lipid peroxidation, and decreased levels of superoxide dismutase and catalase. Journal of Experimental Botany, 32, 93-101.

Harborne, J.B., (1973). Phytochemical Methods, Phytochemical Methods. Springer Netherlands, Dordrecht. https://doi.org/10.1007/978-94-009-5921-7

Heath, R.L., Packer, L., (1968). Photoperoxidation in isolated chloroplasts. Archives of Biochemistry and Biophysics, 125, 189-198.

Jagetiya, B., Soni, A., Yadav, S., (2013). Effect of nickel on plant water relations and growth in green gram. Indian Journal of Plant Physiology, $18,372-376$.

Jana, S., Choudhuri, M.A., (1981). Glycolate metabolism of three submersed aquatic angiosperms: Effect of heavy metals. Aquatic Botany, $11,67-77$.

Kapoor, D., Rattan, A., Bhardwaj, R., Kaur, S., Gupta, A., Manoj, (2016). Antioxidative defense responses and activation of phenolic compounds in Brassica juncea plants exposed to cadmium stress. International Journal of Green Pharmacy, 10, 228-234.

Kieth, L.H., (1980). EPA's priority pollutants: where they come from where they're going. In AIChE Symp. Ser., Water 77, 249.

Kulkarni, S.J., Kaware, J.P., (2013). Review on research for removal of phenol from wastewater. International Journal of Scientific Research, 3, 1-5.

Lawlor, D.W., (2002). Limitation to photosynthesis in water-stressed leaves: Stomata vs. Metabolism and the role of ATP. Annals of Botany, $89,871-885$.

Lee, D.H., Lee, C.B., (2000). Chilling stress-induced changes of antioxidant enzymes in the leaves of cucumber: In gel enzyme activity assays. Plant Science, $159,75-85$.

Lee, S.Y., Ahmad, S.A., Mustapha, S.R., Ong-Abdullah, J., (2017). Ability of Ipomoea aquatica forssk. to remediate phenol in water and effects of phenol on the plant's growth. Pertanika Journal of Science \& Technology, 25, 441-452.

Lichtenthaler, H.K., (1987). Chlorophylls and carotenoids: Pigments of photosynthetic biomembranes. Methods in Enzymology, 148, 350-382.

Liu, N., Zhong, G., Zhou, J., Liu, Y., Pang, Y., Cai, H., Wu, Z., (2019). Separate and combined effects of glyphosate and copper on growth and antioxidative enzymes in Salvinia natans (L.) All. Science of the Total Environment, 655, 1448-1456.

Lutts, S.., Kinet, J.M.., Bouharmont, J., (1996). NaCl-induced senescence in leaves of rice (Oryza sativa L.) cultivars differing in salinity resistance. Annals of Botany, 78, 389-398.

Maehly, A.C., Chance, B., (1954). The assay of catalases and peroxidases. Methods of Biochemical Analysis, 1, 357-424.

Mahadevan A., Sridhar R. (1982). Methods in Physiological Plant Pathology. Sivakami Publication, Madras.

Mashkani, S.G., Ghazvini, P.T.M., (2009). Biotechnological potential of Azolla filiculoides for biosorption of Cs and Sr: Application of micro-PIXE for measurement of biosorption. Bioresource Technology, 100, 1915-1921.

Martinez, V., Mestre, T.C., Rubio, F., Girones-Vilaplana, A., Moreno, D.A., Mittler, R., Rivero, R.M., (2016). Accumulation of flavonols over hydroxycinnamic acids favors oxidative damage protection under abiotic stress. Frontiers of Plant Science, 7, 838.

Mittler, R., (2002). Oxidative stress, antioxidants and stress tolerance. Trends Plant Science, 7, 405-410.

Paisio, C.E., Fernandez, M., González, P.S., Talano, M.A., Medina, M.I., Agostini, E., (2018). Simultaneous phytoremediation of chromium and phenol by Lemna minuta Kunth: A promising biotechnological tool. International Journal of Environmental Science and Technology, 15, 37-48.

Park, J., Brown, M.T., Han, T., (2012). Phenol toxicity to the aquatic macrophyte Lemna paucicostata. Aquatic Toxicology, 106-107, 182-188. 
Prasad, S.M., Singh, A., (2011). Metabolic responses of Azolla pinnata to cadmium stress: Photosynthesis, antioxidative system and phytoremediation. Journal of Chemical Ecology, 27, 543-555.

Prasad, S.M., Singh, A., Singh, P., (2015). Physiological, biochemical and growth responses of Azolla pinnata to chlorpyrifos and cypermethrin pesticides exposure: a comparative study. Journal of Chemical Ecology, 31, 285-298.

Plummer, T., (1978). An Introduction to practical biochemistry (2nd edition): By David T. Plummer. McGraw-Hill Book Company (U.K.) Ltd., London 1978. Wiley Online Library.

Rai, P.K., (2008). Phytoremediation of $\mathrm{Hg}$ and Cd from industrial effluents using an aquatic free floating macrophyte Azolla pinnata. International Journal of Phytoremediation, 10, 430-439.

Raja, W., Rathaur, P., John, S., Ramteke, P., Dar, R., (2012b). Effect of monocrotophos on electrolytic leakage, proline content and nitrogen metabolism of floating pteridophyte Azolla microphylla. The Holistic Approach to Environment, 2, 111-120.

Raja, W., Rathaur, P., Ramteke, P.W., (2012a). Detrimental upshot of different concentrations of endosulfan on growth and lipid peroxidation of aquatic pteridophyte Azolla. Jordan Journal of Biological Sciences, 5, 331-336.

Rama Devi, S., Prasad, M.N.V., (1998). Copper toxicity in Ceratophyllum demersum L. (Coontail), a floating macrophyte: Response of antioxidant enzymes and antioxidants. Plant Science, 138, 157-165.

Rana, V., Ram, S., Nehra, K., (2017). Proline biosynthesis and its role in abiotic stress. International Journal of Agriculture Innovations and Research. 6, 23191473.

Ren, Y., Miao, M., Meng, Y., Cao, J., Fan, T., Yue, J., Xiao, F., Liu, Y., Cao, S., (2018). DFR1-mediated inhibition of proline degradation pathway regulates drought and freezing tolerance in Arabidopsis. Cell Reports, 23, 3960-3974.

Roberts, A.E., Boylen, C.W., Nierzwicki-Bauer, S.A., (2014). Effects of lead accumulation on the Azolla caroliniana-Anabaena association. Ecotoxicology and Environmental Safety, 102, 100-104.

Samarina, L., Matskiv, A., Simonyan, T., Koninskaya, N., Malyarovskaya, V., Gvasaliya, M., Malyukova, L., Tsaturyan, G., Mytdyeva, A., Martinez-Montero, M.E., Choudhary, R., Ryndin, A., (2020). Biochemical and genetic responses of tea (Camellia sinensis (L.) Kuntze) microplants under mannitol-induced osmotic stress in vitro. Plants, 9, 1795.

Sánchez-Viveros, G., Ferrera-Cerrato, R., Alarcón, A., (2011). Short-term effects of arsenate-induced toxicity on growth, chlorophyll and carotenoid contents, and total content of phenolic compounds of Azolla filiculoides. Water, Air and Soil Pollution, 217, 455-462.

Saxena, I., Srikanth, S., Chen, Z., (2016). Cross talk between $\mathrm{H}_{2} \mathrm{O}_{2}$ and interacting signal molecules under plant stress response. Frontiers of plant science. 7, 570 .

Scragg, A.H., (2006). The effect of phenol on the growth of Chlorella vulgaris and Chlorella VT-1. Enzyme and Microbial Technology, 39, 796-799.

Soares, C., Carvalho, M.E.A., Azevedo, R.A., Fidalgo, F., (2019). Plants facing oxidative challenges - A little help from the antioxidant networks. Environmental and Experimental Botany, 161, 4-25.

Sood, A., Pabbi, S., Uniyal, P.L., (2011). Effects of paraquat on lipid peroxidation and antioxidant enzymes in aquatic fern Azolla microphylla. Russian Journal of Plant Physiology, 58, 667-673.

Sood, A., Prasanna, R., Prasanna, B.M., Singh, P.K., (2008). Genetic diversity among and within cultured cyanobionts of diverse species of Azolla. Folia Microbiologic, 53, 35-43.

Sood, A., Uniyal, P.L., Prasanna, R., Ahluwalia, A.S., (2012). Phytoremediation potential of aquatic macrophyte, Azolla. Ambio 41, $122-137$.

Stewart, A.J., Stewart, R.F., (2008). Phenols, in: Encyclopedia of Ecology. Sven Erik Jorgensen and Brian Fath, Elsevier, 2682-2689.

Stom, D.I., Roth, R., (1981). Some effects of polyphenols on aquatic plants: I. Toxicity of phenols in aquatic plants. Bulletin of Environmental Contamination and Toxicology. 27, 332-337.

Thordal-Christensen, H., Zhang, Z., Wei, Y., Collinge, D.B., (1997). Subcellular localization of $\mathrm{H}_{2} \mathrm{O}_{2}$ in plants. $\mathrm{H}_{2} \mathrm{O}_{2}$ accumulation in papillae and hypersensitive response during the barley-powdery mildew interaction. The Plant Journal, 11, 1187-1194.

Vilvert, E., Contardo-Jara, V., Esterhuizen-Londt, M., Pflugmacher, S., (2017). The effect of oxytetracycline on physiological and enzymatic defense responses in aquatic plant species Egeria densa, Azolla caroliniana, and Taxiphyllum barbieri. Environmental Toxicology and Chemistry, 99, $104-116$.

Wasi, S., Tabrez, S., Ahmad, M., (2013). Toxicological effects of major environmental pollutants: an overview. Environmental Monitoring and Assessment, 185, 2585-2593. 
Wolff, G., Pereira, G., Castro, E., Louzada, J., Coelho, F., (2012). The use of Salvinia auriculata as a bioindicator in aquatic ecosystems: biomass and structure dependent on the cadmium concentration. Brazilian Journal of Biological Sciences, 72, 71-77.

Zazouli, M.A., Mahdavi, Y., Bazrafshan, E., Balarak, D., 2014. Phytodegradation potential of bisphenol A from aqueous solution by Azolla filiculoides. Journal of Environmental Health Science and Engineering, 12, 2-6.

Zhang, Y.-B., Yang, S.-L., Dao, J.-M., Deng, J., Shahzad, A.N., Fan, X., Li, R.-D., Quan, Y.-J., Bukhari, S.A.H., Zeng, Z.-H., (2020). Drought-induced alterations in photosynthetic, ultrastructural and biochemical traits of contrasting sugarcane genotypes. PLoS One, 15, 1-21.

Zhong, W., Wang, D., Wang, Z., (2018). Distribution and potential ecological risk of 50 phenolic compounds in three rivers in Tianjin, China. Environmental Pollution, 235, 121-128.

\section{Figures}

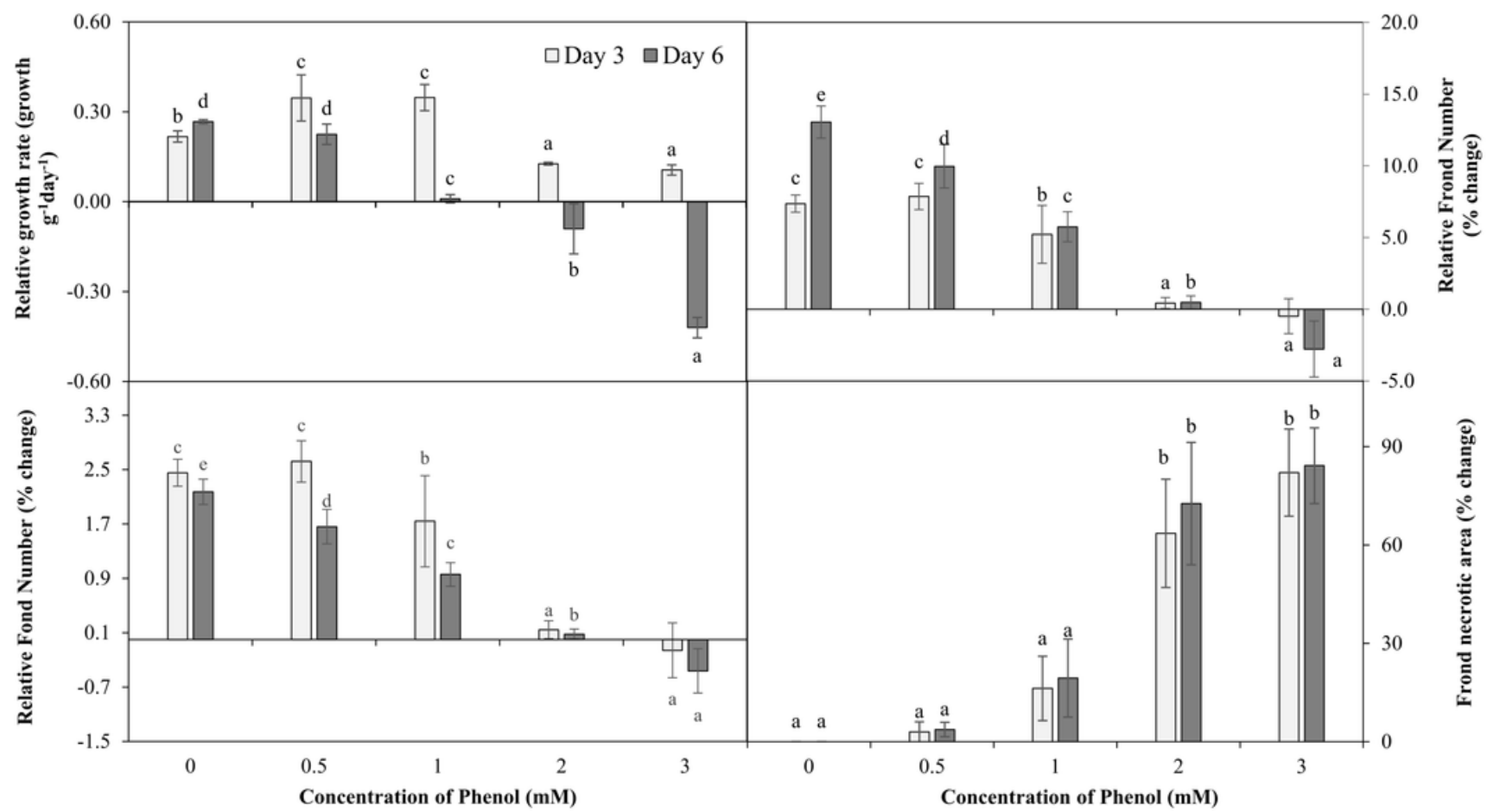

\section{Figure 1}

Status of growth parameters of A. filiculoides plants subjected to different concentrations of phenol. (A) Relative Growth Rate (RGR); (B) Relative Frond Number (RFN); (C) Relative Frond Surface Area (RFSA); (D) Frond Necrotic Area (FNA). All the values are represented by the bars indicate Mean \pm S.D. Different letters above the bar indicates significant differences in the mean values subjected to different concentrations of phenol separately for 3 days and 6 days of exposure. 


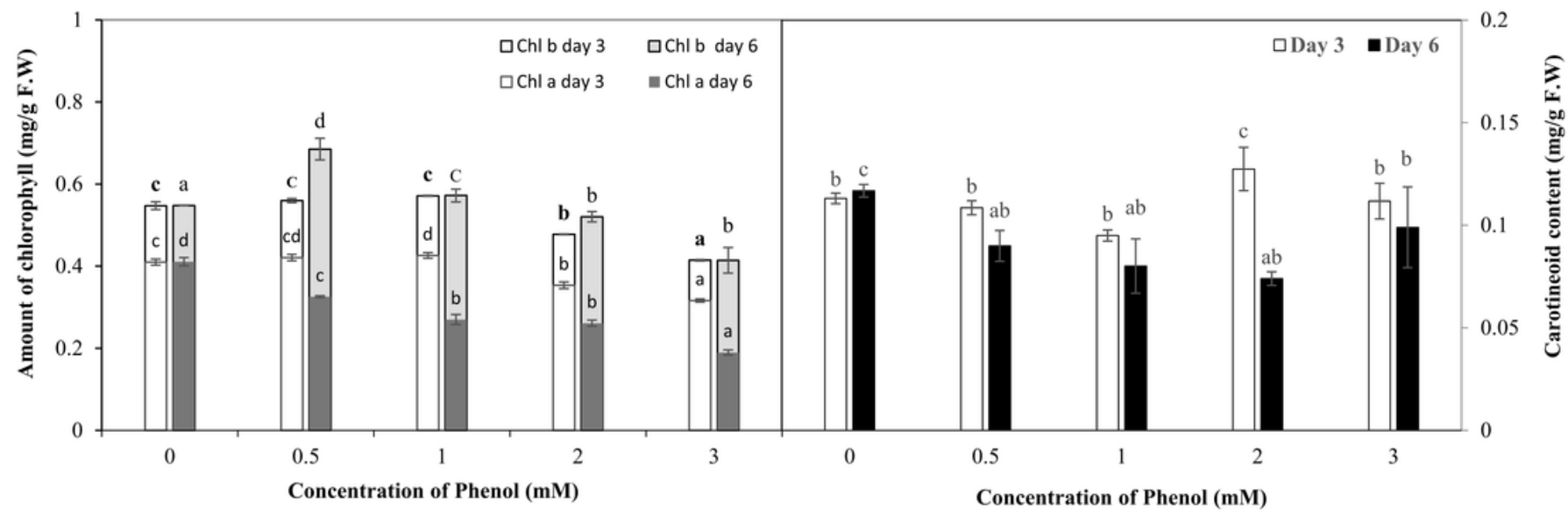

Figure 2

Effect on the pigments of A. filiculoides plants subjected to different concentrations of phenol. (A) Chlorophyll a and b; (B) Carotenoids. All the values are represented by the bars indicate Mean \pm S.D. Different letters above the bar indicates significant differences in the mean values subjected to different concentrations of phenol separately for 3 days and 6 days of exposure.

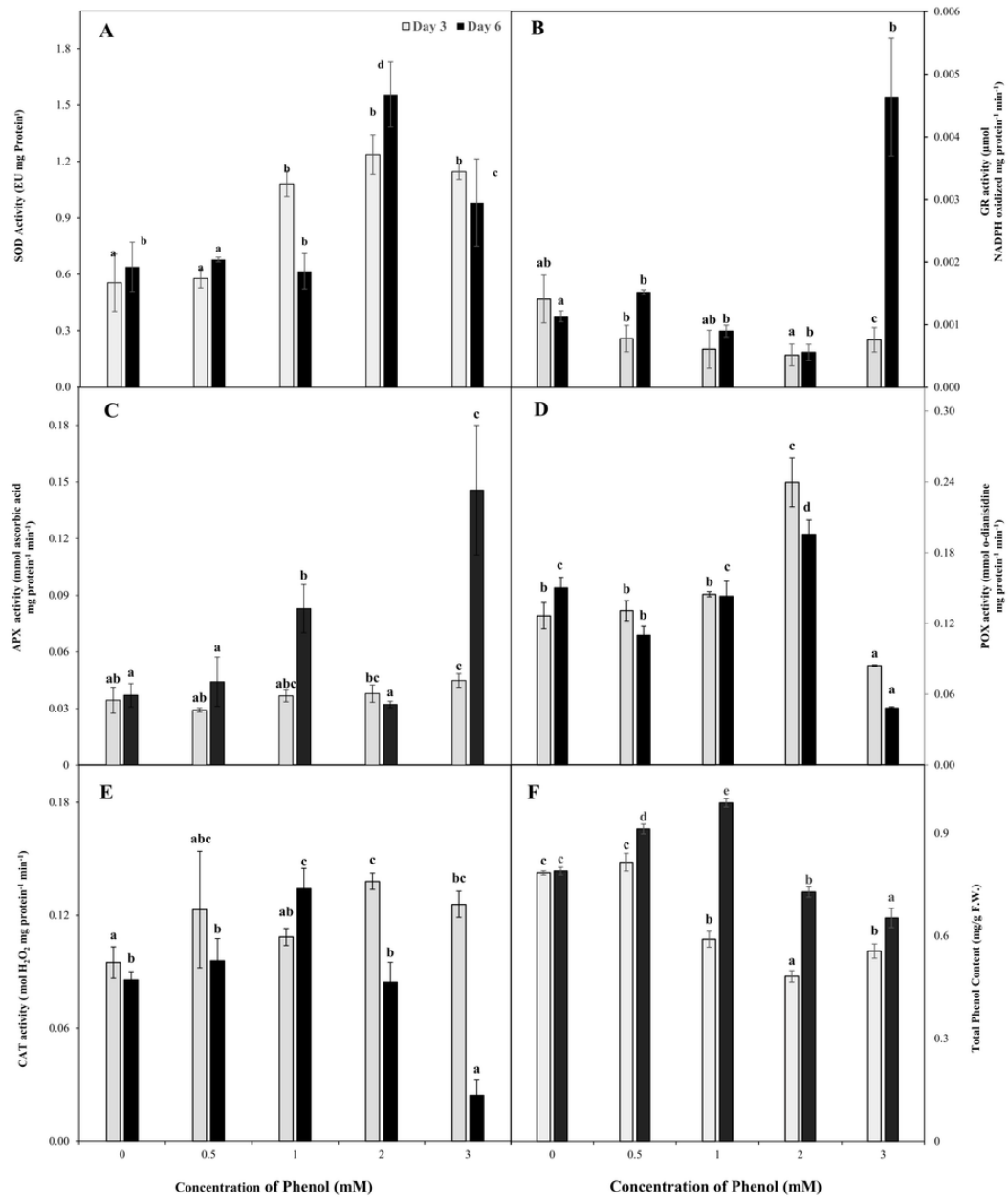

Figure 3

Effect on the activities of antioxidative enzymes and tissue phenol content subjected to different concentrations of phenol. (A) Superoxide dismutase (SOD); (B) Glutathione reductase (GR); (C) Ascorbate peroxidase (APX); (D) Peroxidase (POX); (E) Catalase (CAT); (F) Tissue phenol content. All the values are 
represented by the bars indicate Mean \pm S.D. Different letters above the bar indicates significant differences in the mean values subjected to different concentrations of phenol separately for 3 days and 6 days of exposure.

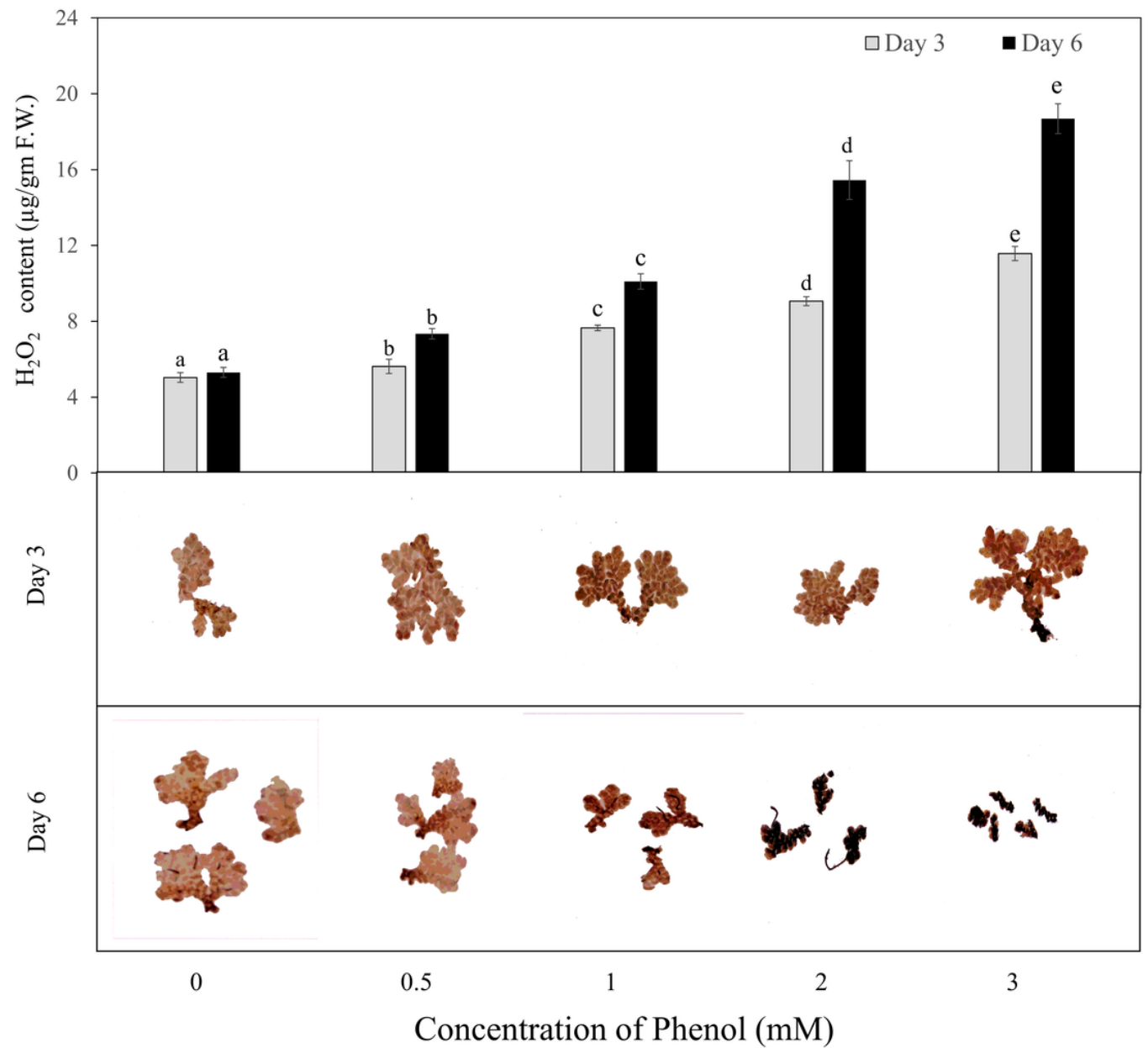

Figure 4

Effect on the accumulation of $\mathrm{H} 2 \mathrm{O} 2$ (A) and in situ localization of $\mathrm{H} 2 \mathrm{O} 2$ (B) subjected to different concentrations of phenol. All the values in Fig. 4A are represented by the bars indicate Mean \pm S.D. Different letters above the bar indicates significant differences in the mean values subjected to different concentrations of phenol separately for 3 days and 6 days of exposure. In Fig. 4B H2O2 localization is observed as the formation of reddish-brown patches in the fronds due to the polymerization of $\mathrm{H} 2 \mathrm{O} 2$ and DAB. 